\title{
The Relationship between the Values of Leptin, Interlukin-10, and TNFa with Fatigue and Aerobic Capacity in Women with Multiple Sclerosis
}

\section{Motahare Mokhtarzade $^{1 *}$, Rohollah Ranjbar ${ }^{1}$, Nastaran Majdinasab ${ }^{2}$}

${ }^{1}$ Department of Sport Physiology, Faculty of Physical Education, Shahid Chamran University, Ahvaz, Iran

${ }^{2}$ Department of Neurology, Faculty of Medicine, Jundishapour University of Medical Sciences, Ahvaz, Iran

\section{A BSTRACT}

Introduction: Multiple sclerosis (MS) is a demyelinating autoimmune disease with an unclear mechanism. MS is characterized by axonal damage, demyelination, and increased inflammation. Cytokines play important roles in the pathogenesis of MS. The purpose of this study was to investigate the relationship between some cytokines with fatigue and aerobic capacity in women with MS. Materials and Methods: 45 women with MS participated in this study. The levels of serum leptin, TNF $\alpha$, and IL-10 were measured by ELISA method. Fatigue and aerobic capacity were evaluated by fatigue severity scale questionnaire and ergometer cycle incremental test, respectively. Results: Leptin had a significant positive correlation with TNF $\alpha$, body mass index and fatigue in these patients. Furthermore, leptin had a significant negative correlation with aerobic capacity and aerobic capacity had a significant negative correlation with fatigue and disability scale. While TNF $\alpha$ had a significant positive correlation with fatigue, interlukin-10 had no correlation with other factors. Conclusion: Improvement on aerobic capacity and regular physical activity can be accompanied with decrease in production of inflammatory cytokines and fatigue. This may increase the quality of life in people with MS.

Key words:

1. Multiple Sclerosis

2. Fatigue

3. Cytokines

*Corresponding Author: Motahare Mokhtarzade

E-mail:mz.mokhtarzade@yahoo.com 


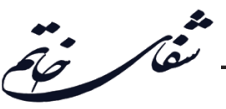

\title{
ارتباط بين مقادير ليتين، اينترلوكين --1 و TNFa با خستكى و ظرفيت هوازى در زنان مبتلا به مالتيِيل اسكلروز
}

\author{
مطهره مختارزاده'"، روح اله رنجبر'، نسترن مجدى نسب' \\ 'كروه فيزيولوزى ورزشى، دانشكده تربيت بدنى و علوم ورزشى، دانشكاه شهيد حمران، اهواز، ايران

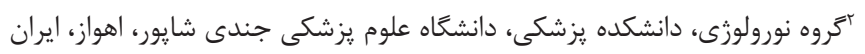

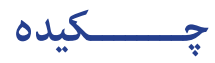

مقدمه: مالتيبل اسكلروز يك بيمارى دميلينه كنندهُ خود ايمن با مكانيسم ناشناخته است. مالتيبل

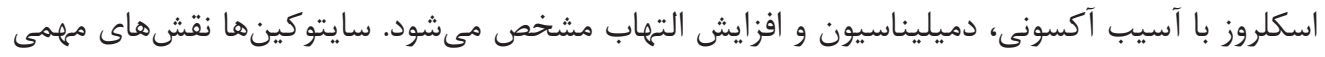

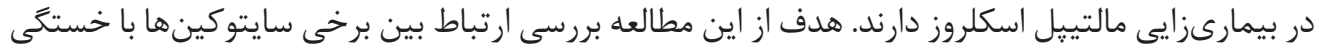

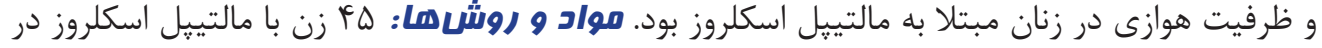

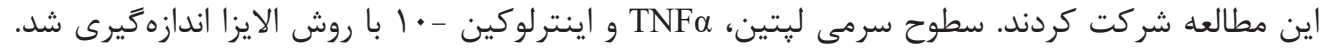

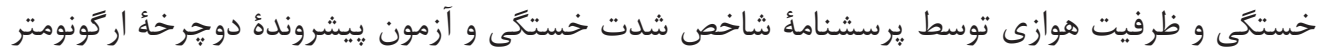

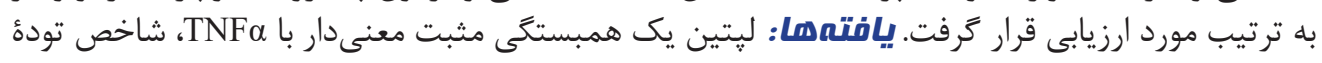

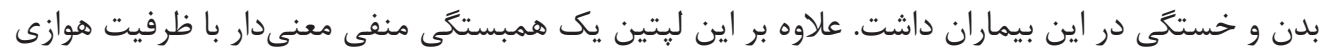

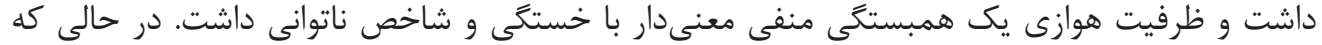
TNFa

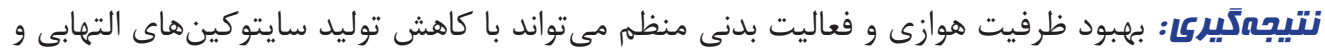

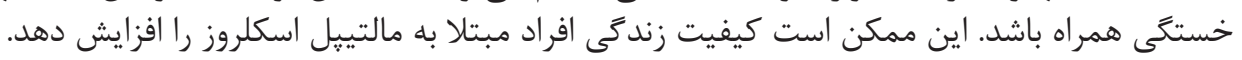

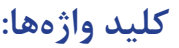

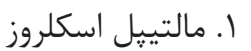

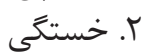

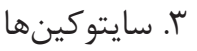




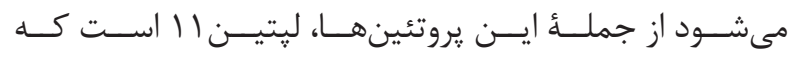

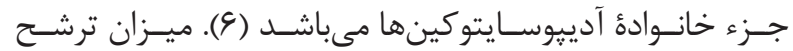

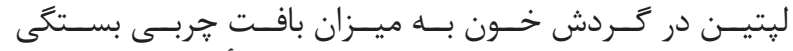

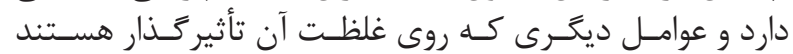

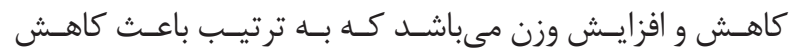

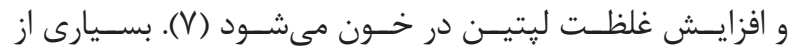

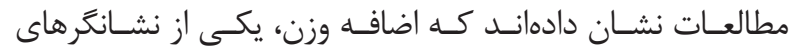

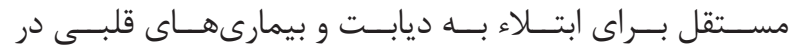

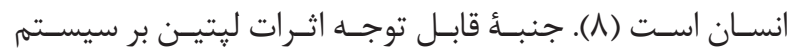

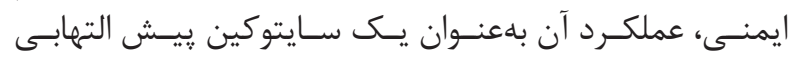

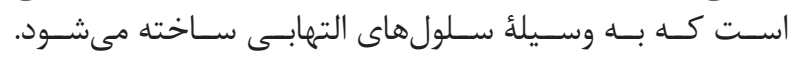

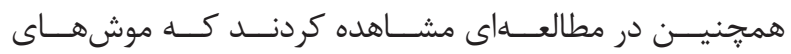

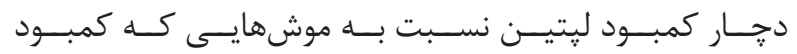

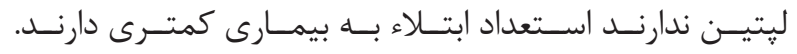

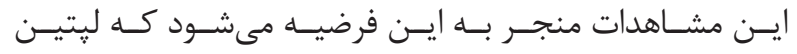

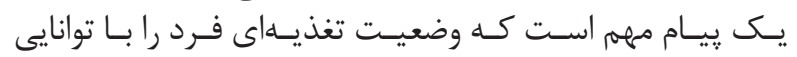

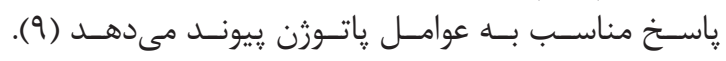

ايسـن هورمــون التهابـى احتمــالاً در بيشــرفت بيمــارى MS

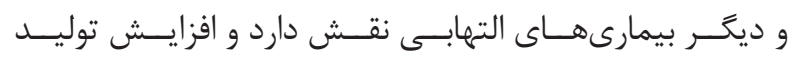

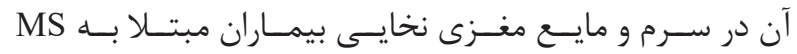

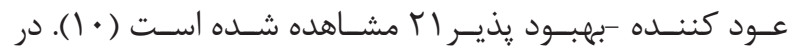

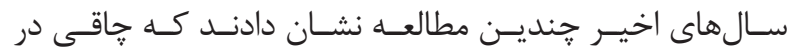

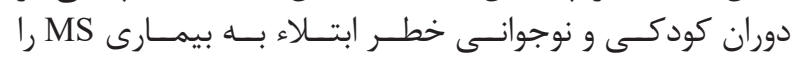

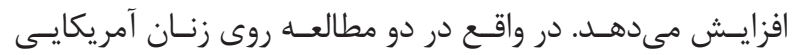

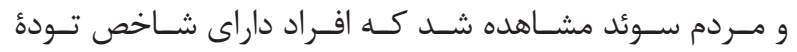

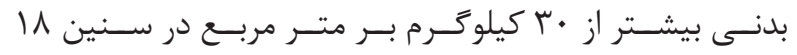

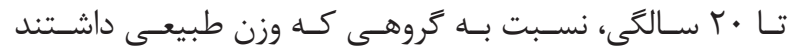

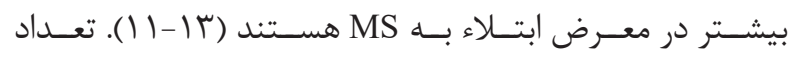

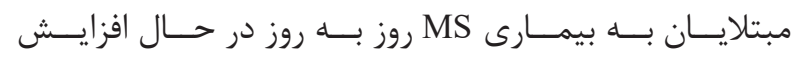

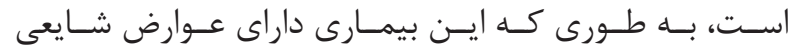

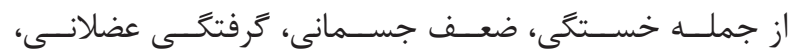

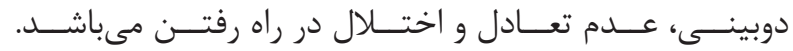

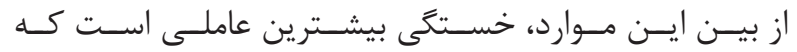

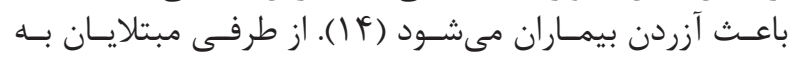
MS

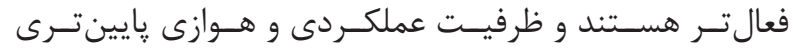

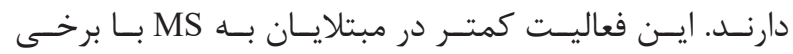

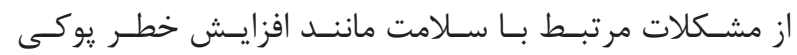

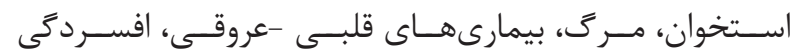

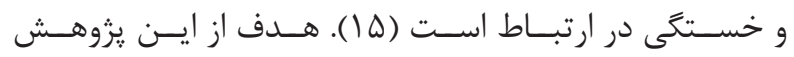

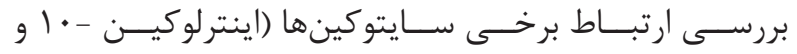
(TNF

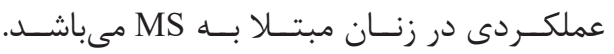

مواد و روشها - - ماد

${ }^{1}$ Multiple sclerosis (MS)

${ }^{2}$ Central nervous system

${ }^{3}$ Pathogenicity

${ }^{4} \mathrm{~T}$ helper

${ }^{5}$ Interleukin

${ }^{6}$ Tumor necrosis factor alpha

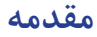

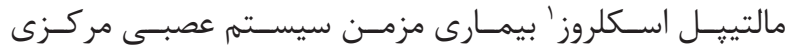

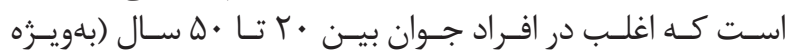

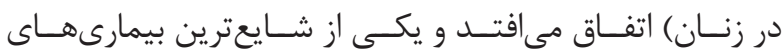

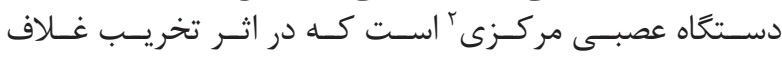

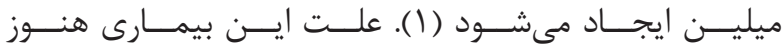

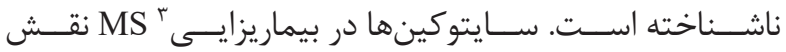

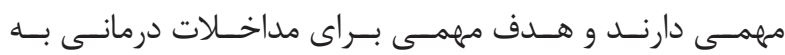

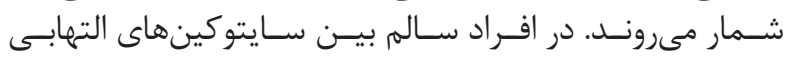

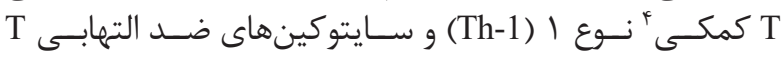

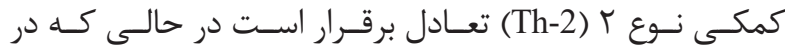

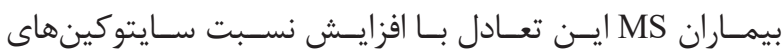

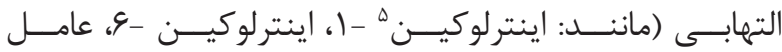

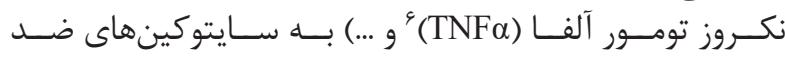

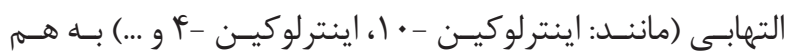

مى خـــورد (r) (ب).

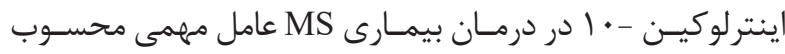

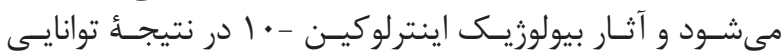

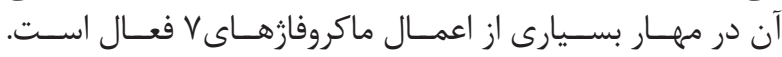

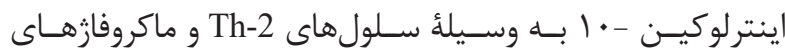

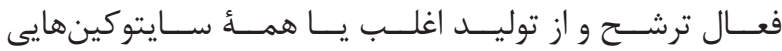

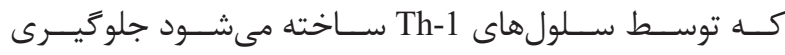

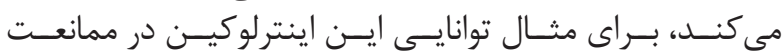

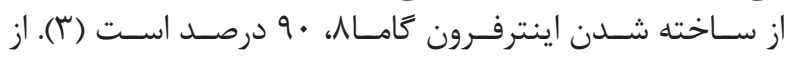

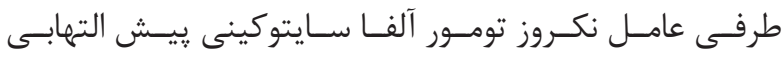

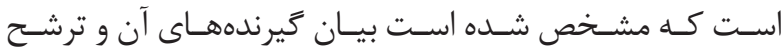

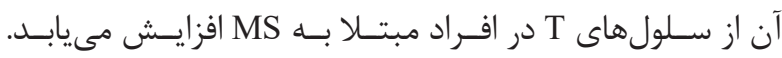

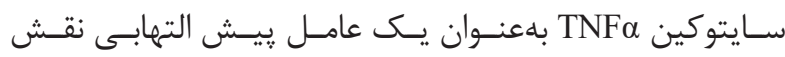

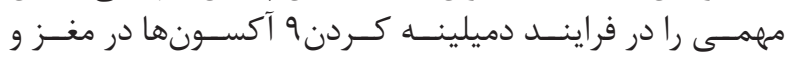

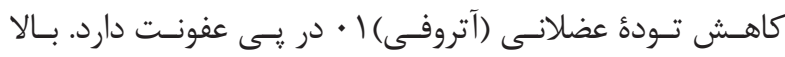

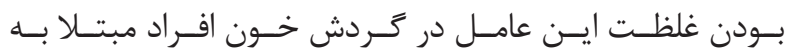

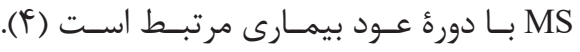

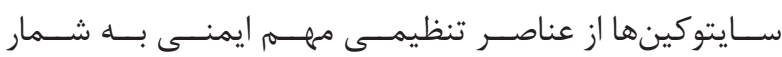

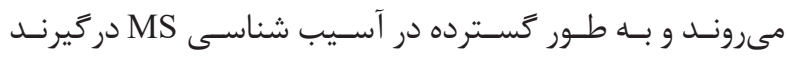

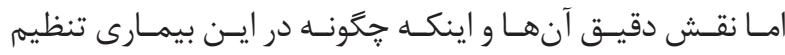

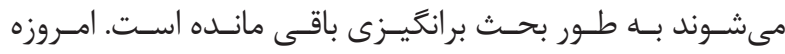

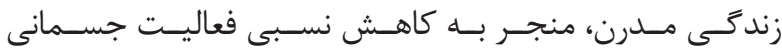

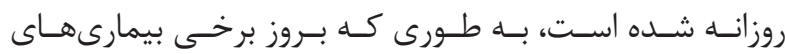

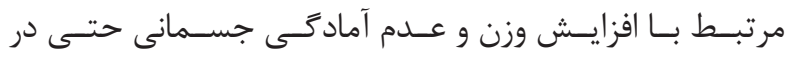

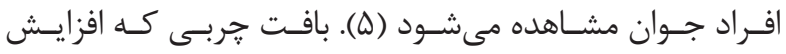

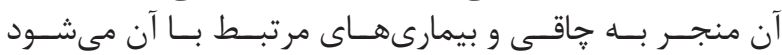

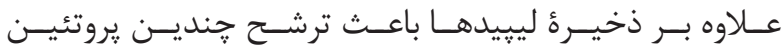

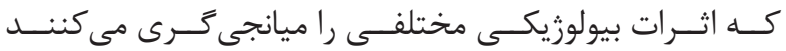

\footnotetext{
${ }^{7}$ Macrophage

${ }^{8}$ Interferon gamma

${ }^{9}$ Demyelination

${ }^{10}$ Atrophy

${ }^{11}$ Leptin

${ }^{12}$ Relapsing-remitting MS
} 


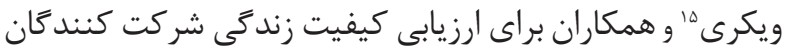

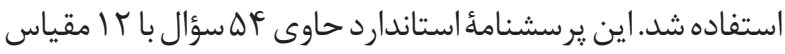

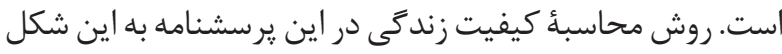

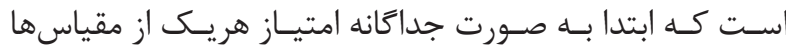

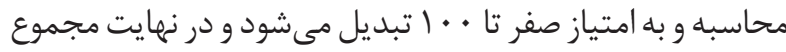

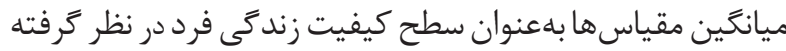

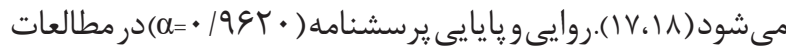

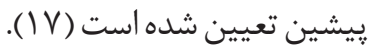

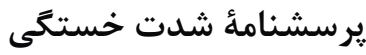

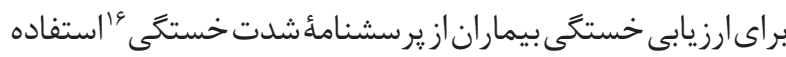

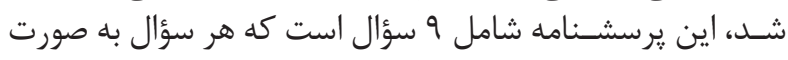

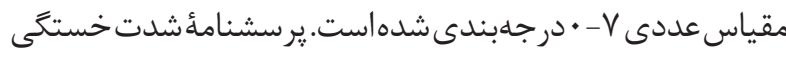

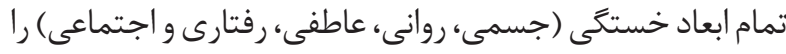

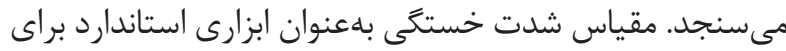

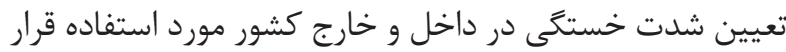

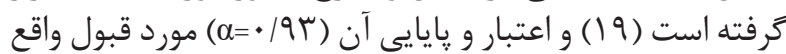

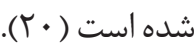

\section{ير سشنامة سطح فعاليت بدنى}

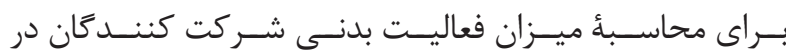

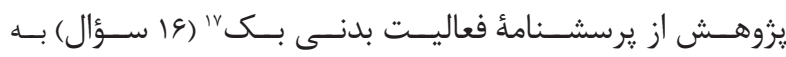

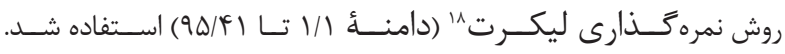

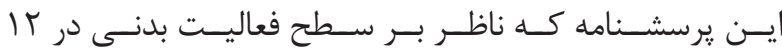

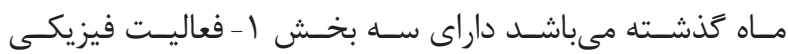

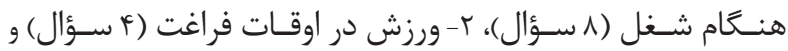

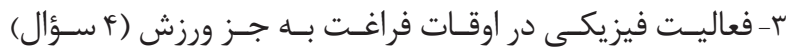

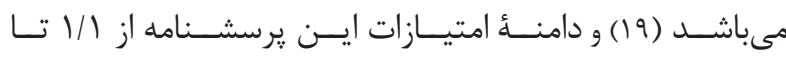

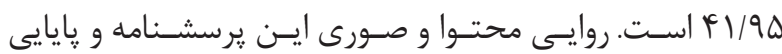

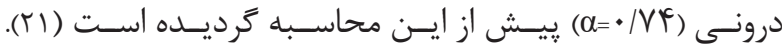

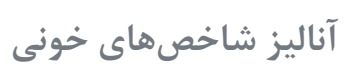

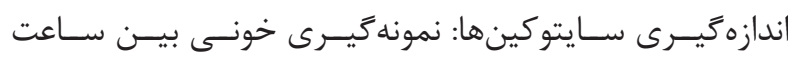

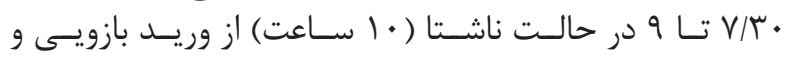

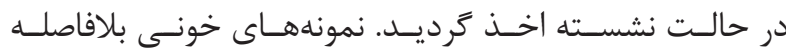

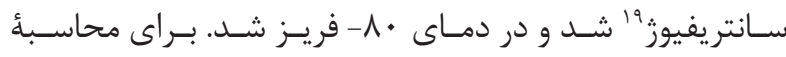

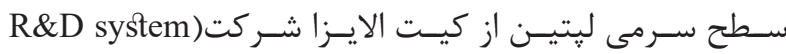
(Minneapolis, MN, USA

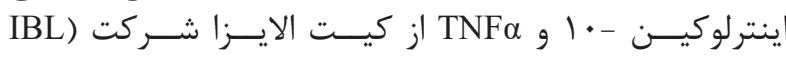
International GMBH, Hamburg, Germany

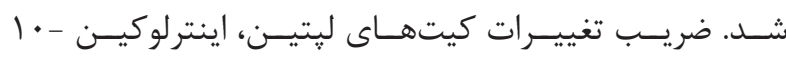
ب TNF

$$
\text { تحليل آمارى }
$$

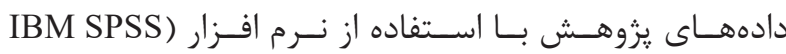
SPSS (Statistics, version rl, Armonk, NY

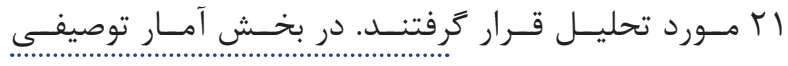

\footnotetext{
${ }^{13}$ Storer and Davis

${ }^{14}$ MS quality of life-54

${ }^{15}$ Vickery

${ }^{16}$ Fatigue severity scal
}

\section{شر كت كنند}

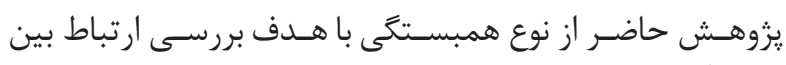

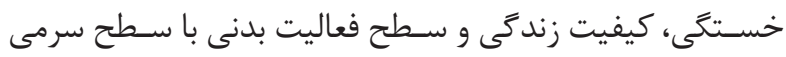

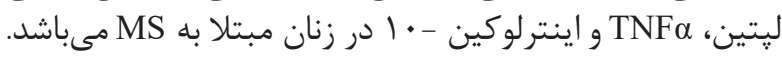

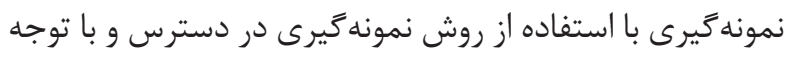

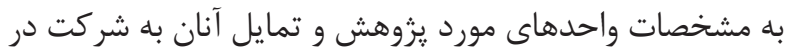

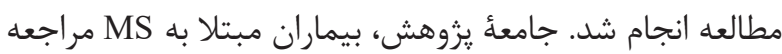

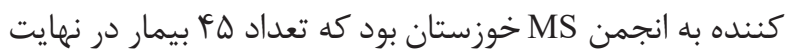

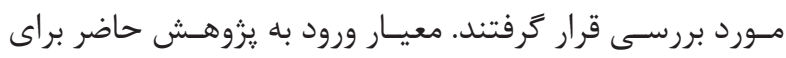

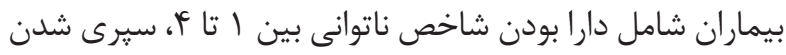

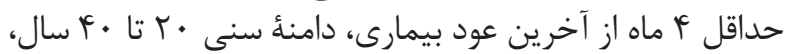

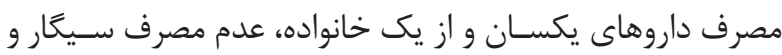
نداشـتن رزيم غذايى خاص مى بـاشد.

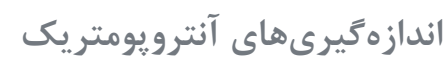

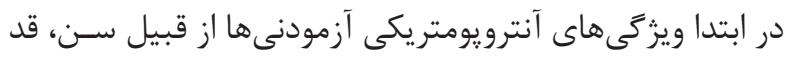

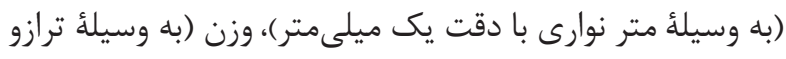

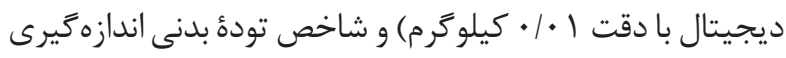

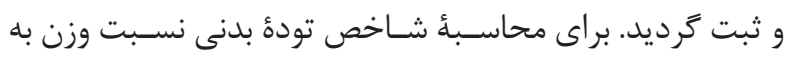

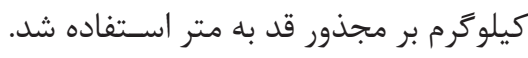

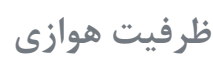

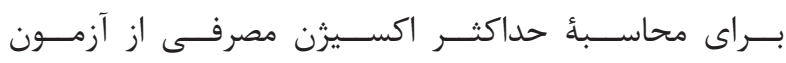

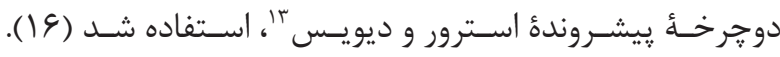

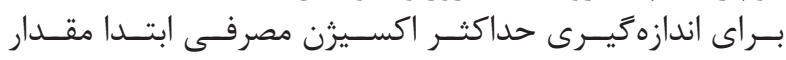

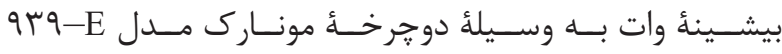

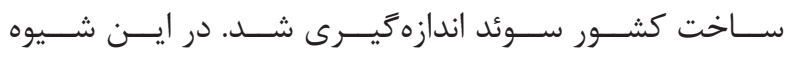

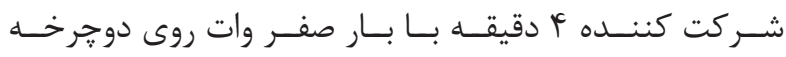

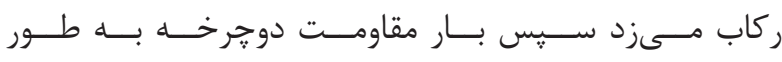

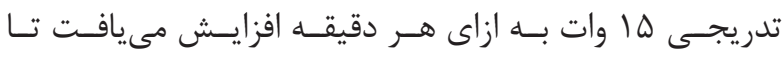

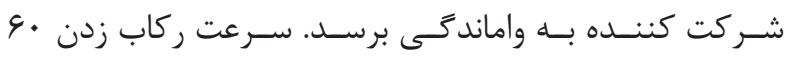

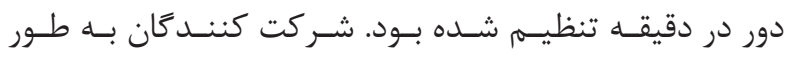

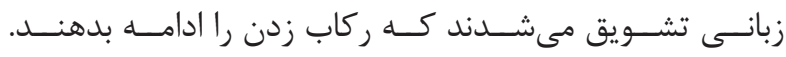

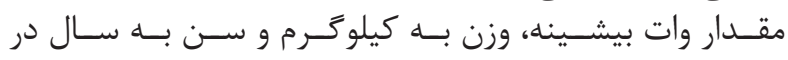

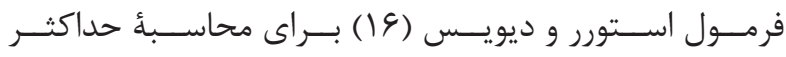

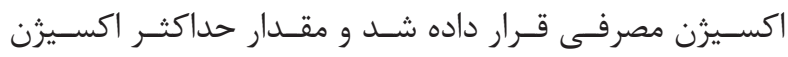

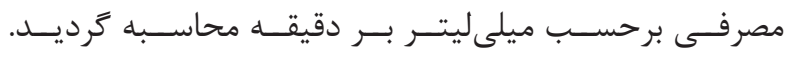

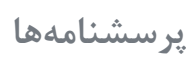

شركت كنندكان يرسشنامهاى كه شامل مشخصات جمعيتشناختى

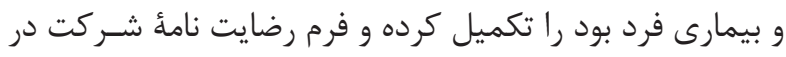

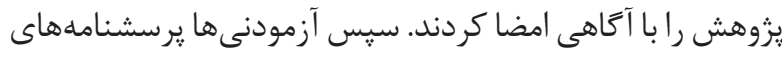

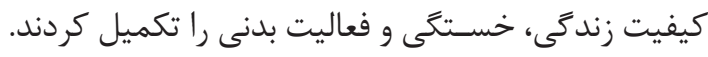

يرسشنامة كيفيت زندكى

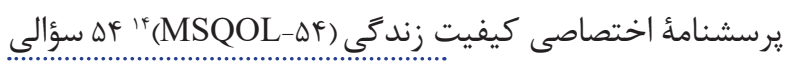

${ }^{17}$ Bech

${ }^{18}$ Likert

${ }^{19}$ Centrifuges 


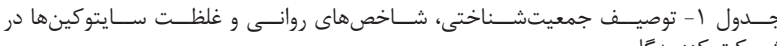

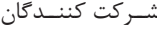

\begin{tabular}{|c|c|c|}
\hline انحراف استاندارد & ميانگين & شاخص \\
\hline $1 \cdot 1 \cdot r$ & $\varepsilon q / q p$ & وزن (كيلوكرم) \\
\hline זس/. & $r / \cdot 1$ & شاخص ناتوانى \\
\hline 11/4 & $\Delta r|\varphi|$ & كيفيت زندكى \\
\hline T/Tr & IV/TD & 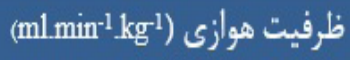 \\
\hline $1 / N \Delta$ & $T / V I$ & اينترلوكين-· | (ng/ml) \\
\hline l/gF & $\Gamma / \varphi$. & (ng/ml) TNF $\alpha$ \\
\hline$\Delta / I V$ & $w / / \cdot \Lambda$ & سن (سال) \\
\hline$r / 1 T$ & $r \mathrm{r} / \mathrm{q \Lambda}$ & شاخص تودة بدن (Kg/m²) \\
\hline $19 / T \Delta$ & $r \Delta / \Delta T$ & سطح فعاليت بنى \\
\hline $11 / 11$ & TI/TF & خستكى \\
\hline $0 / 99$ & WNAT & ليتين (ng/ml) \\
\hline
\end{tabular}

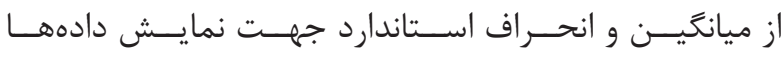

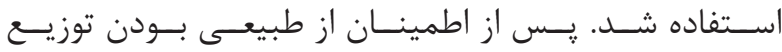

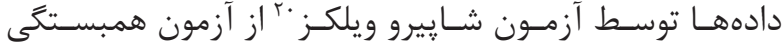

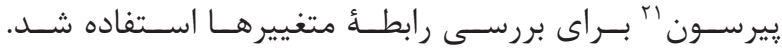

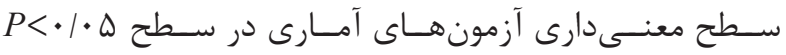

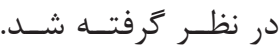

افتهها

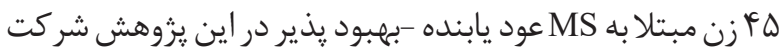

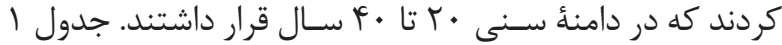

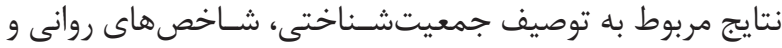

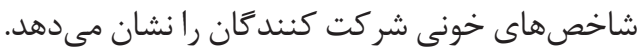
نتايج حاصل از جدول r نشان داد كه رابطة معنى دار و مستقيمى

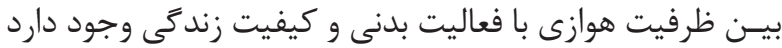

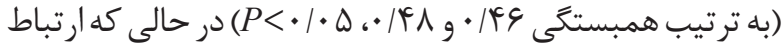

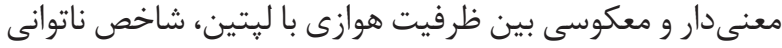

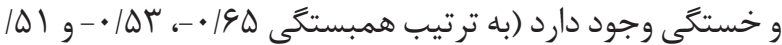

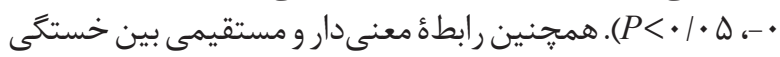

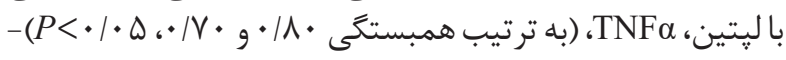

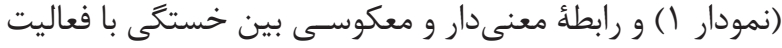

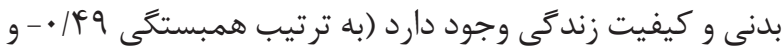

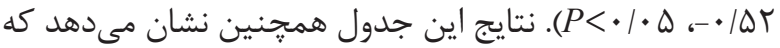

جدول Y - همبستگى سايتوكينها، عامل هاى روانى و عملكردى.

\begin{tabular}{|c|c|c|c|c|c|c|c|c|c|c|c|}
\hline شاتواتى ش شاخص & وزن & شوده بنسى & خستكى & زيفيت & فعاليت & اينترلوكين- & $\mathrm{TNF} \alpha$ & ليتين & ظرفيت & & \\
\hline$-\cdot / \Delta r$ & $-\cdot / r \Delta$ & $-\cdot \pi r$ & $-\cdot|\Delta| \lambda$ & $\cdot / 4 \lambda$ &.$/ 48$ &.$/ 11$ & $-\cdot / \pi$ & -.190 & & همبستكَى & \multirow{2}{*}{ هرفيت } \\
\hline$* \cdot 1 \cdots 1$ & $* .1 .91$ &.$/ 14$. & $*+\cdots 1$ & $* \cdot \cdots V$ & $* / .14$ &. $\mid 481$ &.$/ 19 \Lambda$ & $* \cdot 1 \cdots 1$ & & معنى دارى & \\
\hline$\cdot \pi T$ & $\cdot / 4 V$ & . & $\cdot / V$ & $-\cdot / 1 \mathrm{~V}$ & $-\cdot / 4 V$ & $-\cdot|r|$ & $\cdot / \Delta \Delta$ & & -.190 & همبستكى & \multirow{2}{*}{ لِتين } \\
\hline.$/ \cdot \Delta F$ & $* \cdot \cdots 1$ & $* / \cdots r$ & * $\cdot / \cdots 1$ &.$/ 1 \% \Delta$ & $* / .11$ & $\cdot / 1 \Delta \varphi$ & * $\cdot 1 \cdots 1$ & & 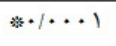 & معنى دارى & \\
\hline$\cdot / 1 \mathrm{~V}$ & . &.$/ 14$ & $\cdot / \Lambda$. & $-\cdot / T F$ & $-\cdot / 4$ & $-\cdot / \pi$ & & $\cdot / \Delta \Delta$ & $-\cdot / \pi \cdot$ & همبستخى & \multirow{2}{*}{$\mathrm{TNF} \alpha$} \\
\hline.$/ 1 T V$ & $* 1.9 \mathrm{~V}$ & . & $* / \cdots)$ & $\cdot / \pi 90$ &.$/ 1 F \Delta$ & $\cdot / 1 \wedge \mathrm{V}$ & & $*+1 \cdots 1$ &.$/ 19 \Lambda$ & معنى دارى & \\
\hline$-\cdot / T F$ & $-\cdot / T F$ & .118 & $-\cdot / T F$ & $\cdot / \pi 1$ & $\cdot / \pi 1$ & & $-\cdot \pi \cdot$ & $-\cdot / T I$ &.$/ 11$ & همبستئى & \multirow{2}{*}{ اينترلوكين- } \\
\hline$\because 91$ &.$/ 1 \mathrm{rA}$ & $\cdot / \pi \wedge$ & $\cdot 11 \cdot 4$ & $. / 4 \mid \varepsilon$ & - TET & & $\cdot / 1 \wedge \mathrm{V}$ & $\cdot / 1 \Delta \varphi$ &. $\mid 481$ & معنى دارى & \\
\hline$-\cdot / \Gamma \wedge$ & $-\cdot / r F$ & $-\cdot / \pi q$ & $-\cdot / 4 q$ & $\cdot|\Delta|$ & & $\cdot|\pi|$ & $-\cdot / / 1$ & $-\cdot / \& V$ & $\cdot 148$ & همبستيكى & \multirow{2}{*}{ فعاليت } \\
\hline . RET & .1 .99 & $\cdot / \cdot \wedge \mathrm{V}$ & 㭗. $1 \cdots r$ & $* \cdot \cdots r$ & & . &.$/ 14 \Delta$ & *ै. $1.1 T$ & * & معنى دارى & \\
\hline$-\cdot / / 1$ & $-\cdot / 19$ & $-\cdot / T \cdot$ & $-\cdot / \Delta T$ & & $\cdot / \Delta \mid$ & $\cdot / \pi \mid$ & $-\cdot / T r$ & $-\cdot / 1 V$ & $\cdot / 4 \wedge$ & همبستخّى & \multirow{2}{*}{ زيفيت } \\
\hline$\cdot / 1 \Delta 9$ & $\cdot \pi V F$ & $\cdot / 1 F \Delta$ & *. & & $* / \cdots r$ & $. / 4 \mid \varepsilon$ & $\cdot / \pi 90$ &.$/ 1 F \Delta$ & $* / \cdots V$ & معنى دارى & \\
\hline$\cdot / \Delta 9$ &.$/ 4 q$ & $\cdot / \pi \Lambda$ & & $-\cdot / \Delta T$ & $-\cdot / 4 q$ & $-\cdot / T F$ & $\cdot / \Lambda$ & $\cdot / V$ & $-\cdot|\Delta|$ & همبستى & \multirow{2}{*}{ خستكى } \\
\hline * $\cdot 1 \cdots 1$ &.$/ 19 \vee$ & $.1 \cdot 9$. & & * .1 .14 & * $\cdot 1 \cdot r$ & $\cdot 11 \cdot 4$ & 粗 $|\cdots|$ & * $\cdot 1 \cdots 1$ & $* \cdot \cdots 1$ & معنى دارى & \\
\hline .119 & .199 & & $\cdot / \pi \Lambda$ & $-\cdot \pi$ & $-\cdot / \pi \varphi$ & .119 & $\cdot / 14$ & ret & $-\cdot / r r$ & همبستخى & \multirow{2}{*}{ شاخص } \\
\hline$\cdot / r V F$ & $*+\cdots 1$ & & $\cdot 1 \cdot 9$. & $\cdot / 1 F \Delta$ & $\cdot / \cdot \Lambda \mathrm{V}$ & $\cdot / \pi \Lambda$ & זr/. & $* / \cdots r$ & ./14. & معنى دارى & \\
\hline$\cdot \pi r$ & & .199 & $\cdot / \pi q$ & $-\cdot / 19$ & $-\cdot / T F$ & $-\cdot / T F$ & . & $\cdot / \mathbb{E V}$ & $-\cdot / r \Delta$ & همبستخى & \multirow{2}{*}{ وزن } \\
\hline . /TVQ & & ${ }^{*} \cdot 1 \cdots+1$ &.$/ 198$ & . /TVF & .1 .99 & ./ ג &.$/ \cdot 9 V$ & $* * 1+1$ & $\cdot 1 \cdot 91$ & معنى دارى & \\
\hline & . &.$/ 19$ & $\cdot / \Delta 9$ & $-\cdot|\pi|$ & $-\cdot \cdot / \mu$ & $-\cdot / T r$ & $\cdot / 1 \mathrm{~V}$ & . & $-\cdot / \Delta r$ & همبستكّى & \multirow{2}{*}{ شاخت } \\
\hline 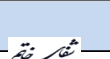 & $\cdot / r \vee q$ & - /TVF & * & $\cdot / 1 \Delta q$ & . TET & $\because .91$ &.$/ 1 T V$ & $\cdot / \cdot \Delta F$ & 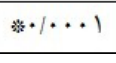 & معنى دارى & \\
\hline
\end{tabular}

${ }^{20}$ Shapiro-Wilkes

${ }^{21}$ Pierson 

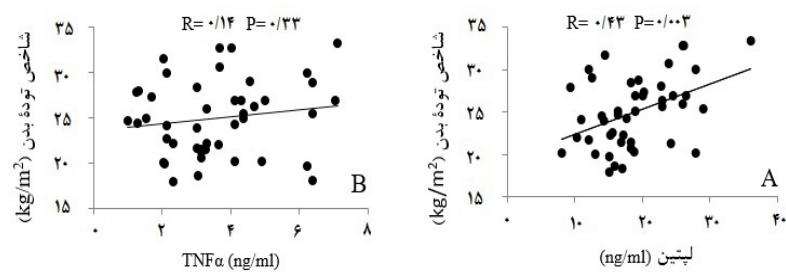

运

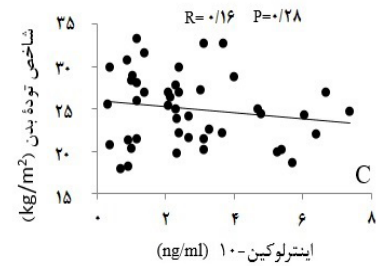

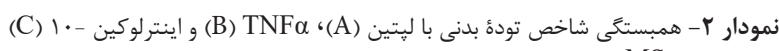

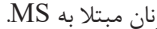
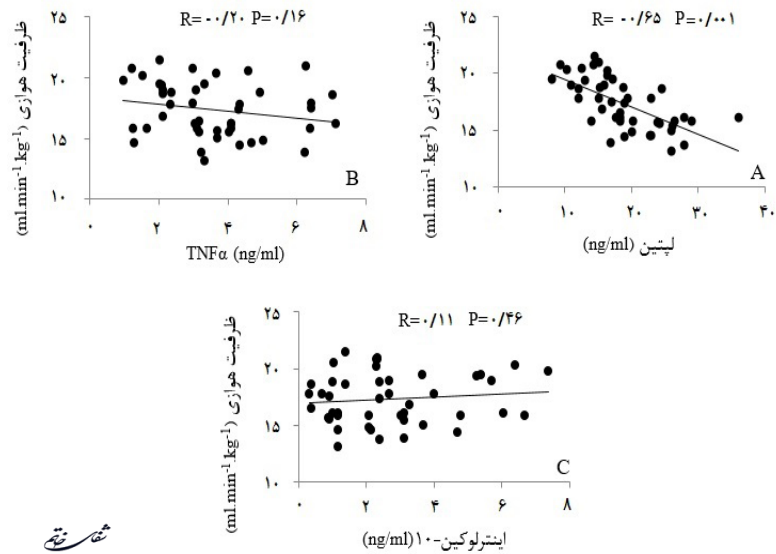

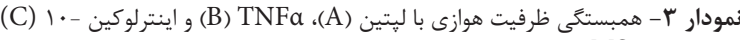

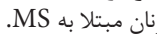

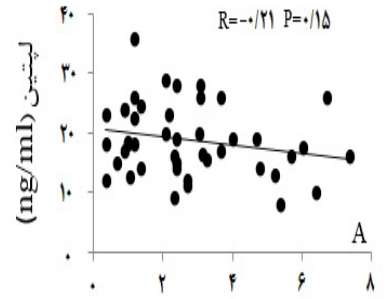

ثق

(1lg/ml)1·-نيترلوكين

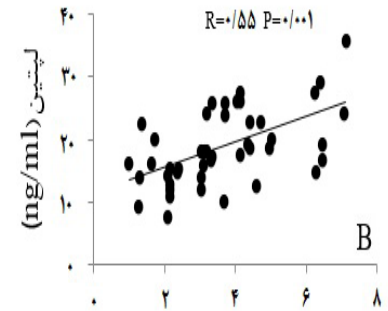

TNFa(ng/ml)

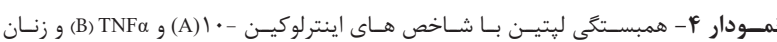

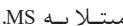

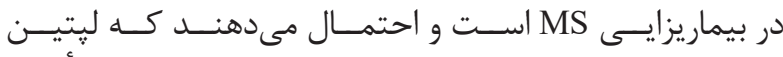

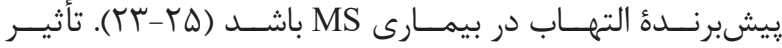

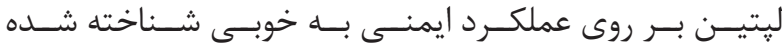

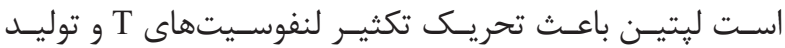

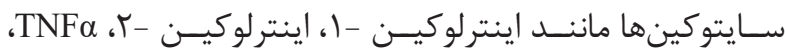

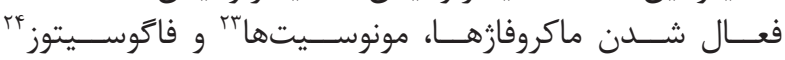

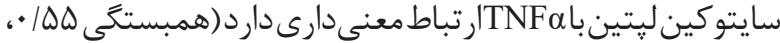

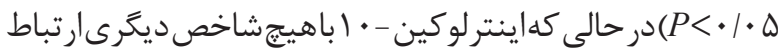

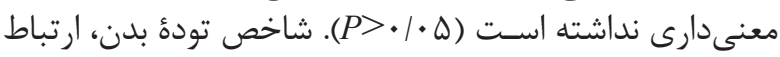

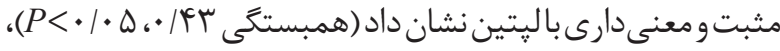

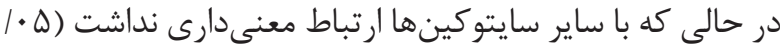

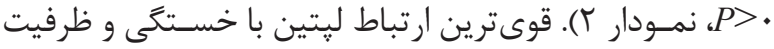

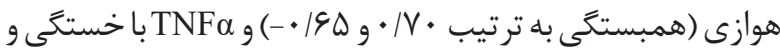

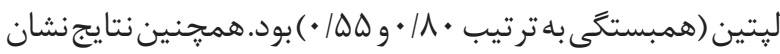

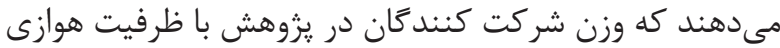

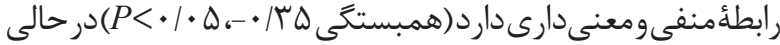

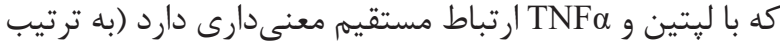

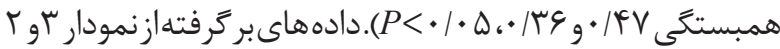

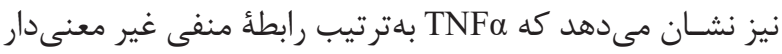

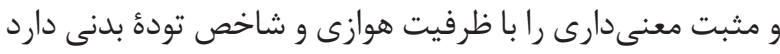

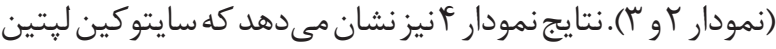

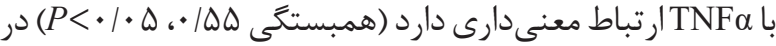

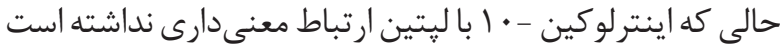

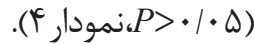

بحث و نتيجه كَيرى

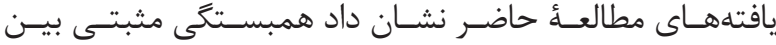

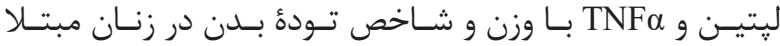

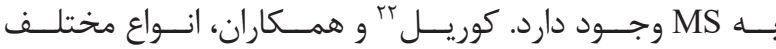

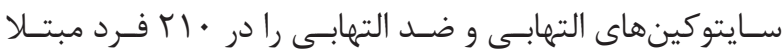

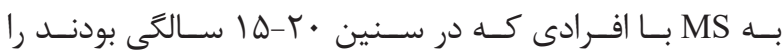

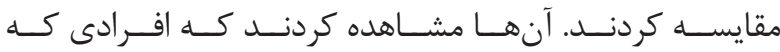

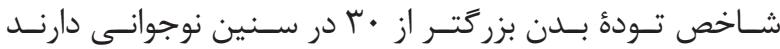

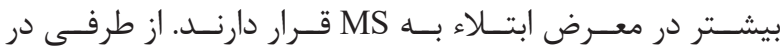

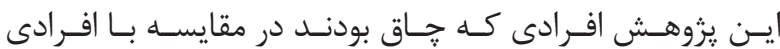

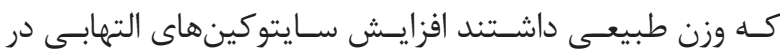

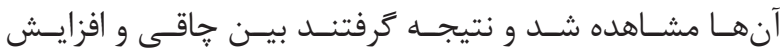

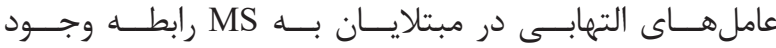

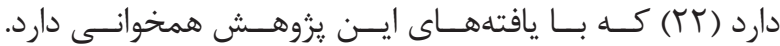

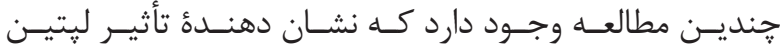
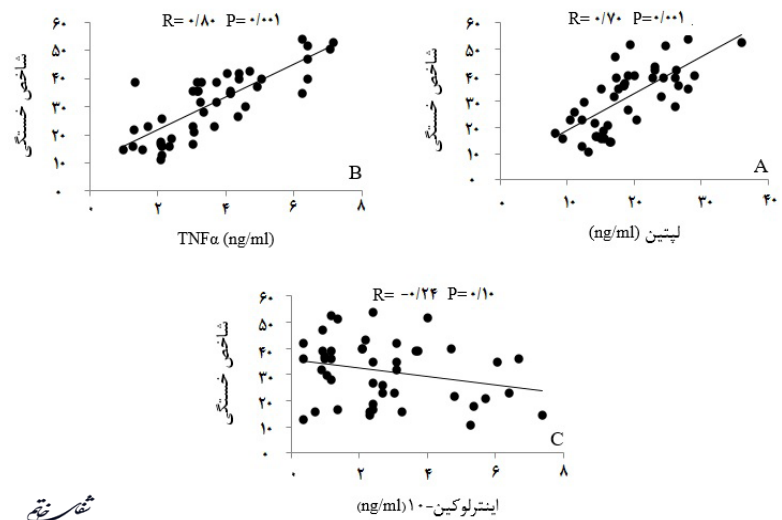

运

اينترلوكين-.(ng/ml)

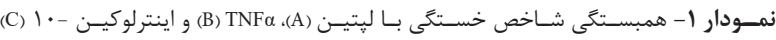




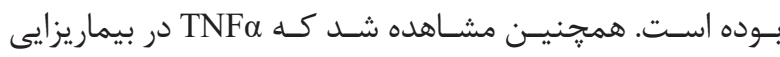

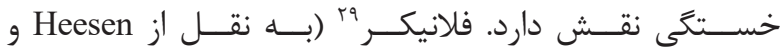

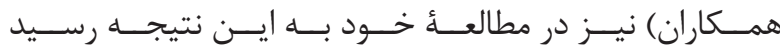

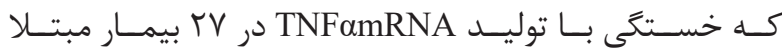

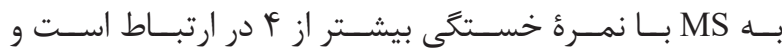

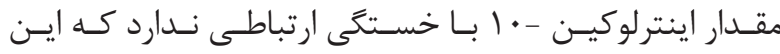

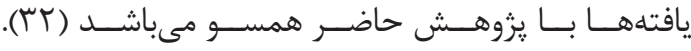

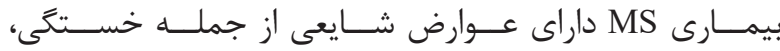

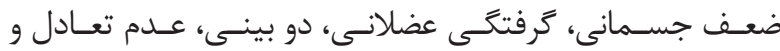

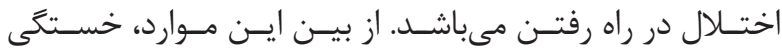

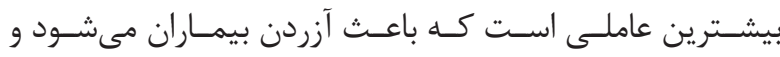

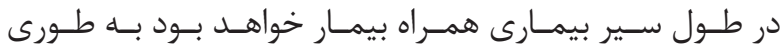

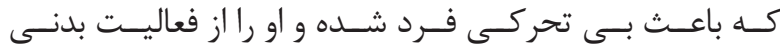

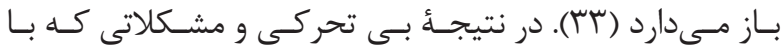

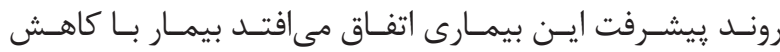

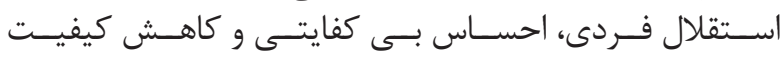

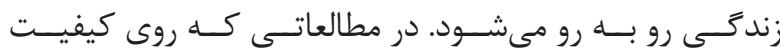

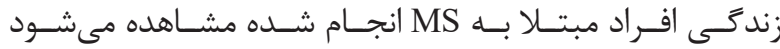

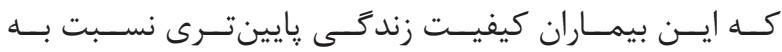

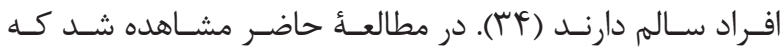

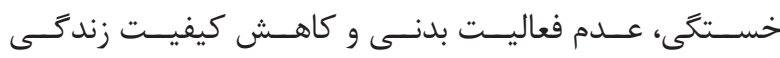

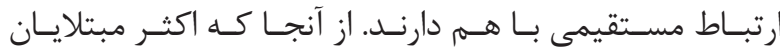

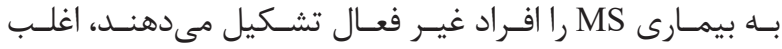

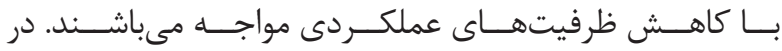

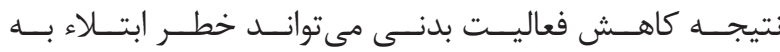

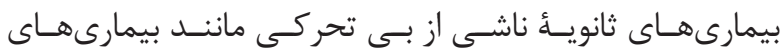

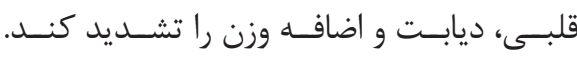

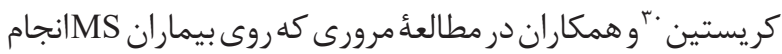

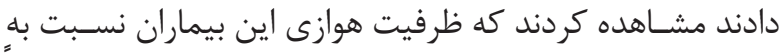

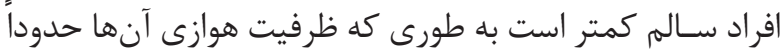

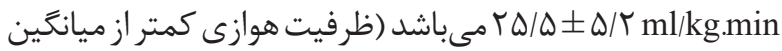

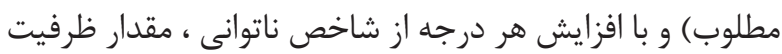

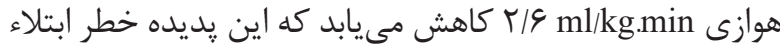
به بيمارى قلبى را بالا مىبرد (هآ).

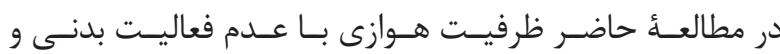

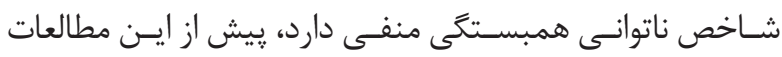

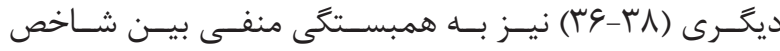

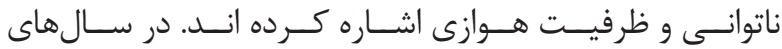

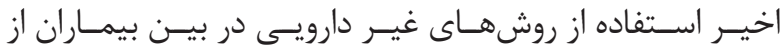

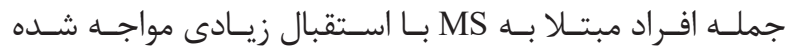

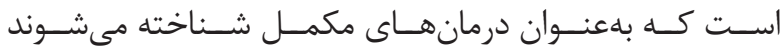

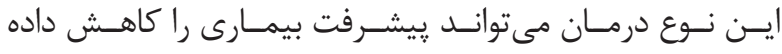

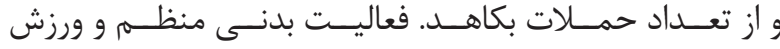

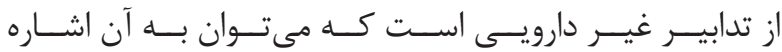

\section{${ }^{23}$ Monocytes}

${ }^{24}$ Phagocytosis

${ }^{25}$ The experimental autoimmune encephalomyelitis

${ }^{26}$ Batocchi
مىشــود (Y)).

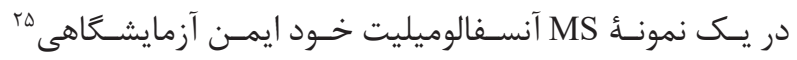

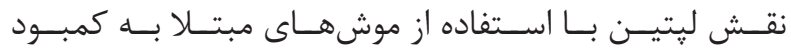

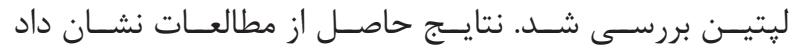

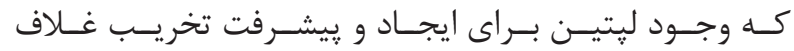

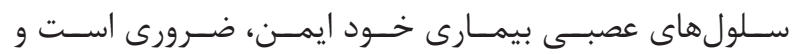

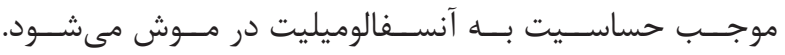

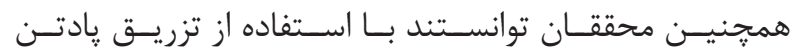

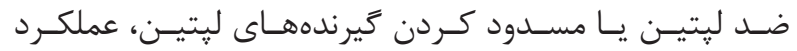

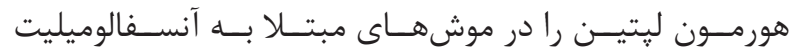

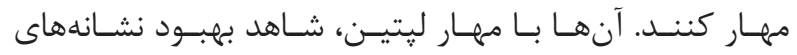

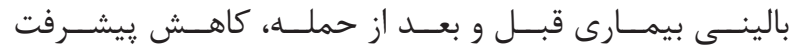

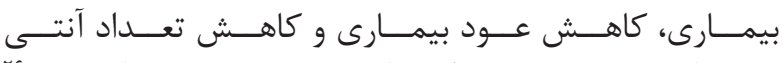

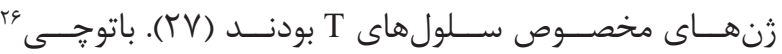

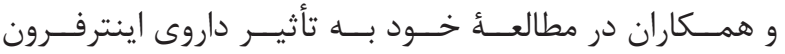

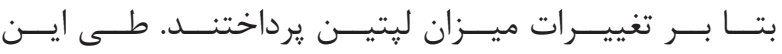

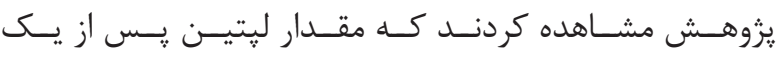

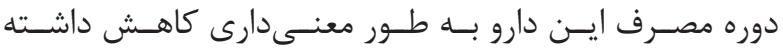

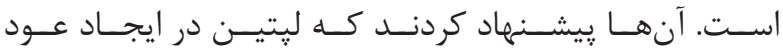

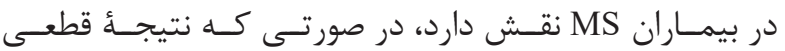

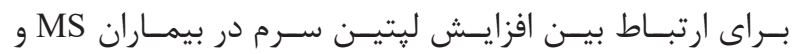

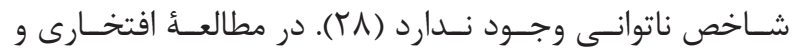

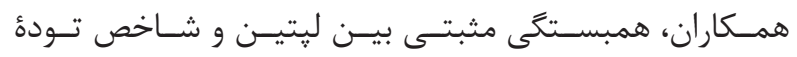

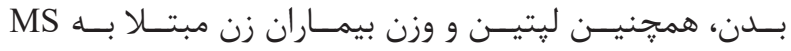

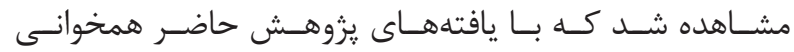

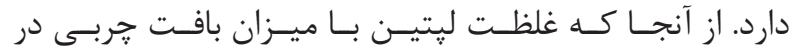

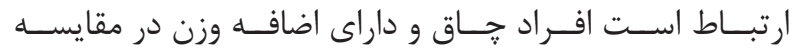

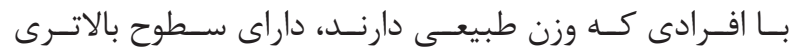

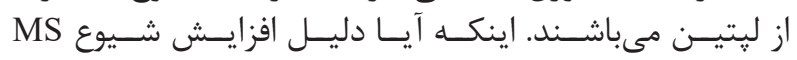

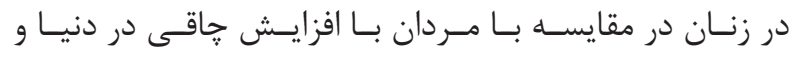

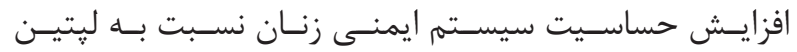

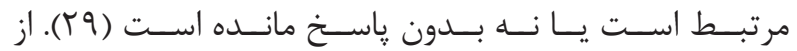

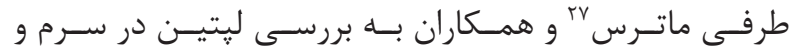

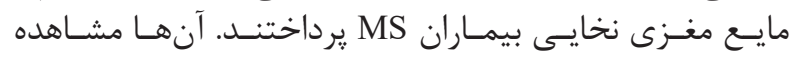

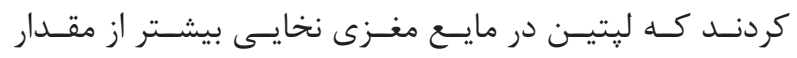

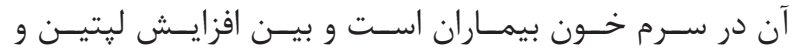

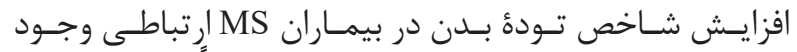

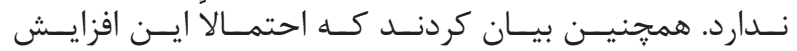

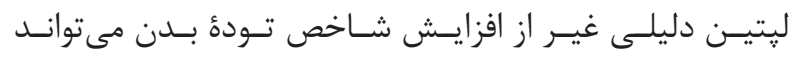

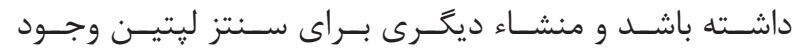

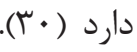

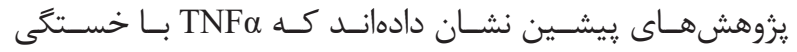

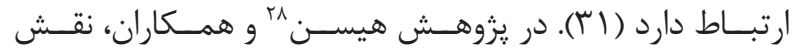

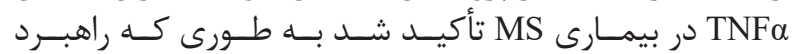

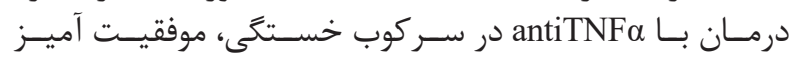

\footnotetext{
${ }^{27}$ Mataresa

${ }^{28}$ Hessen

${ }^{29}$ Flaniker

${ }^{30}$ Christian
} 


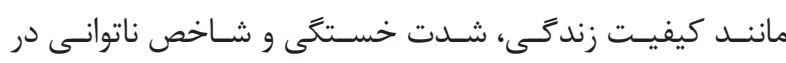

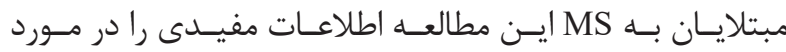

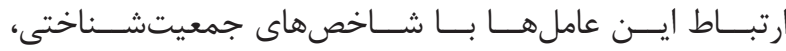

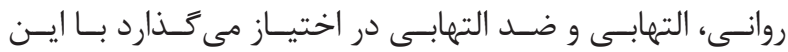

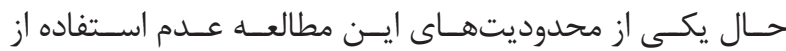

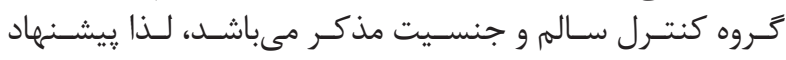

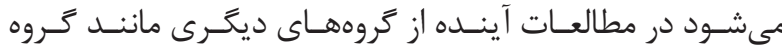

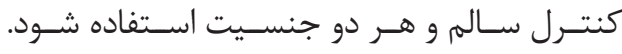

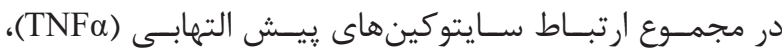

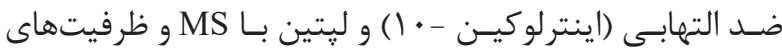

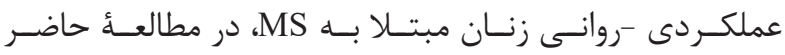

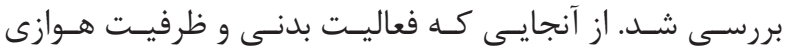

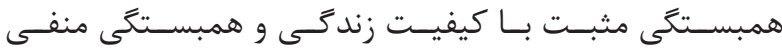

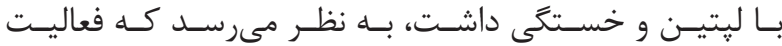

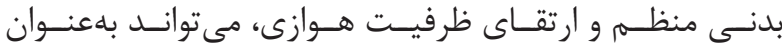

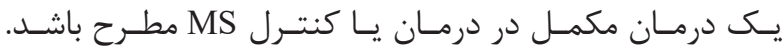

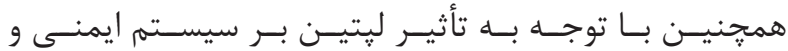

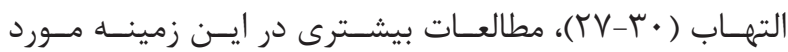

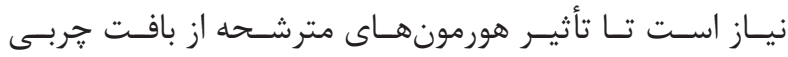

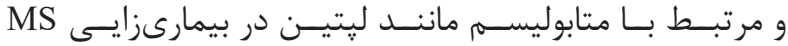

$$
\text { مشـخص شـود. }
$$$$
\text { تشكر و قدردانى تمصن }
$$

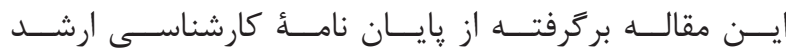

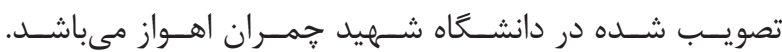

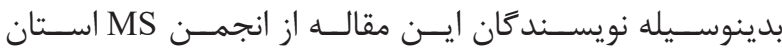

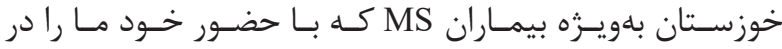

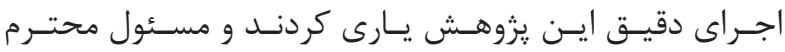

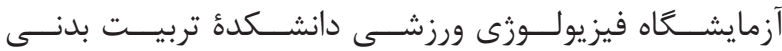

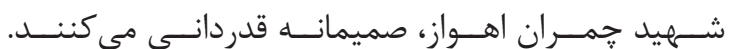

1. Motl RW, Snook EM, Wynn DR, Vollmer T. Physical activity correlates with neurological impairment and disability in multiple sclerosis. J Nerv Ment Dis. 2008; 196(6): 492-5.

2. Castellano V, Patel DI, White LJ. Cytokine responses to acute and chronic exercise in multiple sclerosis. J Appl Physiol. 2008; 104(6): 1697-702.

3. Vojgani M. immunology. $12^{\text {nd }}$ ed. Tehran. Jahad Daneshgahi. 2014; p. 245-94.

4. Pitzalis C, Sharrack B, Gray I, Lee A, Hughes R. Comparison of the effects of oral versus intravenous methylprednisolone regimens on peripheral blood $\mathrm{T}$ lymphocyte adhesion molecule expression, $\mathrm{T}$ cell subsets distribution and TNF alpha concentrations in multiple sclerosis. J Neuroimmun. 1997; 74(1): 62-8.

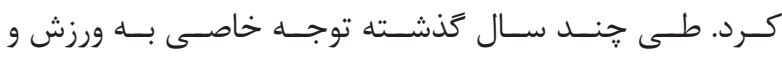

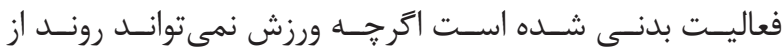

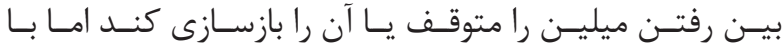

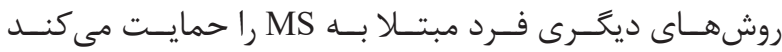

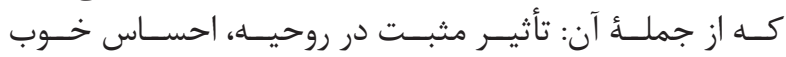

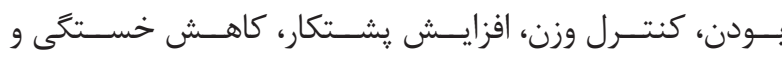

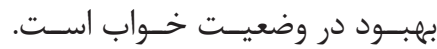

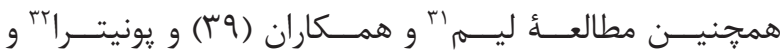

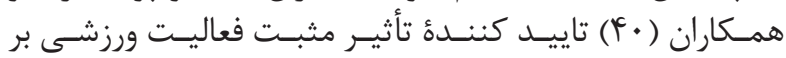

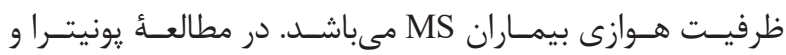

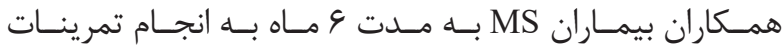

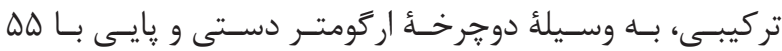

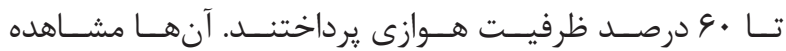

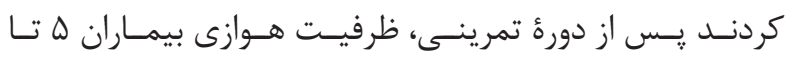

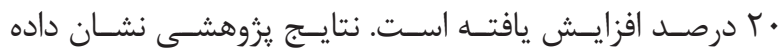

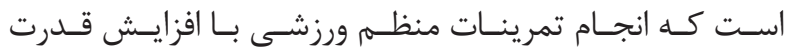

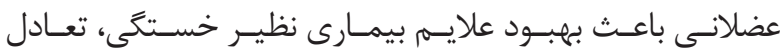

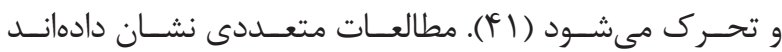

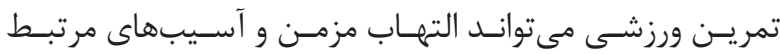

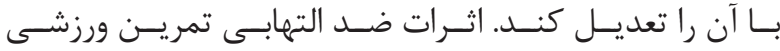

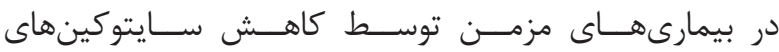

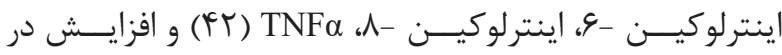

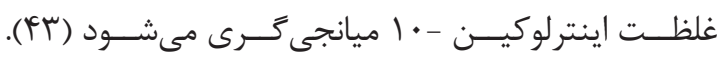

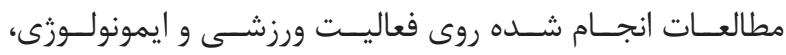

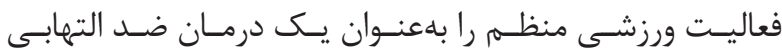

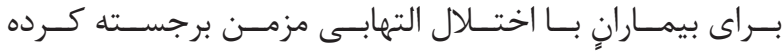

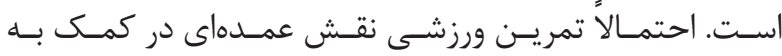

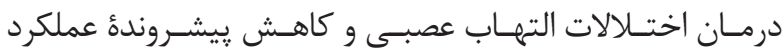

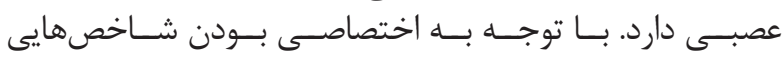

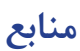

5. Fasshauer M, Klein J, Lossner U, Paschke R.

Interleukin (IL)-6 mRNA expression is stimulated by insulin, isoproterenol, tumour necrosis factor alpha, growth hormone, and IL-6 in 3T3-L1 adipocytes. Horm Metab Res. 2003; 35(03): 147-52.

6. Styne DM. Childhood and adolescent obesity: prevalence and significance. Pediatr Clin North Am. 2001; 48(4): 823-54.

7. Zhang Y, Scarpace PJ. The role of leptin in leptin resistance and obesity. Physiol Behav. 2006; 88(3): 24956.

8. Unal M, Unal D, Baltaci A, Mogulkoc R. Investigation of serum leptin levels and VO2max value in trained young male athletes and healthy males. Acta Physiol 
Hung. 2005; 92(2): 173-9.

9. Najmi M, Hajifaraji M, Mishani MA. The effect of adipokines secreted from adipose tissue on immune function in obese subjects. Iran J Nutria Sci. 2013; 7(5): 887-96.

10. Teryaeva N. Leptin as a neuroprotector and a central nervous system functional stability factor. Neurosci Behav Physiol. 2015; 45(6): 612-8.

11. Munger KL, Chitnis T, Ascherio A. Body size and risk of MS in two cohorts of US women. Neurology. 2009; 73(19): 1543-50.

12. Hedström AK, Olsson T, Alfredsson L. High body mass index before age 20 is associated with increased risk for multiple sclerosis in both men and women. Multiple Sclerosis. 2012; 18(9): 1334-6.

13. Munger KL, Bentzen J, Laursen B, Stenager E, Koch-Henriksen N, Sørensen TI, et al. Childhood body mass index and multiple sclerosis risk: a long-term cohort study. Multiple Sclerosis. 2013; 19: 1323-9.

14. Kargarfard M, Etemadifar M, Asfarjani F, Mehrabi M, Kordavani L. Changes in quality of life and fatigue in women with multiple sclerosis after 8 weeks of aquatic exercise training. J Fundamentals Ment Health. 2010; 12(3): 562-73

15. Langeskov-Christensen M, Heine M, Kwakkel G, Dalgas U. Aerobic capacity in persons with multiple sclerosis: a systematic review and meta-analysis. Sports Med. 2015; 45(6): 905-23.

16. Storer TW, Davis JA, Caiozzo VJ. Accurate prediction of VO2max in cycle ergometry. Med Sci Sports Exerc. 1990; 22(5): 704-12.

17. Vickrey B, Hays RD, Harooni R, Myers LW, Ellison GW. A health-related quality of life measure for multiple sclerosis. Qual Life Res. 1995; 4(3): 187-206.

18. Ghaem H, Haghighi AB, Jafari P, Nikseresht A. Validity and reliability of the Persian version of the multiple sclerosis quality of life questionnaire. Neurol India. 2007; 55(4): 369.

19. Krupp LB, LaRocca NG, Muir-Nash J, Steinberg AD. The fatigue severity scale: application to patients with multiple sclerosis and systemic lupus erythematosus. Arch Neuro. 1989; 46(10): 1121-3.

20. Salehpoor G, Rezaie S, Mozafar H. Psychometric properties of fatigue severity scale in patients with multiple sclerosis. J Kerman Med Sci. 2013; 20(3): 263-278.
21. Tofighi A, Babaei S, Eloon Kashkuli F, Babaei R. The relationship between the amount of physical activity and general health in Urmia medical university students. J Urmia Nurs Mid Fact. 2014; 12(3): 166-72.

22. Correale J, Aguirre MEB, Farez M. Body mass index and multiple sclerosis risk. The role of leptin. Neurology. 2014; 82(10):S24-004.

23. Frisullo G, Angelucci F, Mirabella M, Caggiula M, Patanella K, Nociti V, et al. Leptin enhances the release of cytokines by peripheral blood mononuclear cells from relapsing multiple sclerosis patients. J Clin Immunol. 2004; 24(3): 287-93.

24. Matarese G, Moschos S, Mantzoros CS. Leptin in immunology. J Immunol. 2005; 174(6): 3137-42.

25. Chatzantoni K, Papathanassopoulos P, Gourzoulidou E, Mouzaki A. Leptin and its soluble receptor in plasma of patients suffering from remitting-relapsing multiple sclerosis (MS): In vitro effects of leptin on type-1 and type-2 cytokine secretion by peripheral blood mononuclear cells, T-cells and monocytes of MS patients. J Autoimmun. 2004; 23(2): 169-77.

26. Mata rese G., Procaccini C., De Rosa V. The intricate interface between immune and metabolic regulation: a role for leptin in the pathogenesis of multiple sclerosis. J Leukoc Biol 2008; 84(4): 893-9.

27. Matarese G, Di Giacomo A, Sanna V, Lord GM, Howard JK, Di Tuoro A, et al. Requirement for leptin in the induction and progression of autoimmune encephalomyelitis. J Immunol. 2001; 166(10): 5909-16.

28. Batocchi AP, Rotondi M, Caggiula M, Frisullo G, Odoardi F, Nociti V, et al. Leptin as a marker of multiple sclerosis activity in patients treated with interferon-beta. J Neuroimmunol. 2003; 139(1-2): 150-4.

29. Eftekhari E, Etemadifar M, Ebrahimi A, Baradaran $\mathrm{S}$. The relation between peptide hormones and sex hormone in patients with multiple sclerosis. Iranian J Neurology. 2013; 12(2): 60.

30. Matarese G, Carrieri PB, La Cava A, Perna F, Sanna $\mathrm{V}$, De Rosa V, et al. Leptin increase in multiple sclerosis associates with reduced number of CD4+ CD25+ regulatory T cells. Proc Natl Acad Sci U S A. 2005; 102(14): 5150-5.

31. Matarese G, Procaccini C, De Rosa V. The intricate interface between immune and metabolic regulation: a role for leptin in the pathogenesis of multiple sclerosis. J Leukoc Biol. 2008; 84(4): 893-9.

32. Heesen C, Nawrath L, Reich C, Bauer N, Schulz 


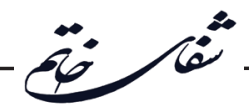

KH, Gold SM. Fatigue in multiple sclerosis: an example of cytokine mediated sickness behavior. J Neurol Neurosurg Psychiatry. 2006; 77(1): 34-9.

33. Kargarfard M, Etemadifar M, Asfarjani F, Mehrabi M, Kordavani L. Changes in quality of life and fatigue in women with multiple sclerosis after 8 weeks of aquatic exercise training. J Fundamentals Ment Health. 2010; 12(3): $562-73$.

34. Tabrizi FM, Radfar M. Fatigue, sleep quality, and disability in relation to quality of life in multiple sclerosis. Int J MS care. 2015; 17(6): 268-74.

35. Langeskov-Christensen M, Heine M, Kwakkel G, Dalgas U. Aerobic capacity in persons with multiple sclerosis: a systematic review and meta-analysis. Sports Med. 2015; 45(6): 905-23.

36. Waschbisch A, Wenny I, Tallner A, Schwab S, Pfeifer $\mathrm{K}$, Mäurer M. Physical activity in multiple sclerosis: a comparative study of vitamin $\mathrm{D}$, brain-derived neurotrophic factor and regulatory $\mathrm{T}$ cell populations. Eur Neurology. 2012; 68(2): 122-8.

37. Motl R, Goldman M. Physical inactivity, neurological disability, and cardiorespiratory fitness in multiple sclerosis. Acta Neurol Scand. 2011; 123(2): 98-104.

38. Heine M, Hoogervorst EL, Hacking HG, Verschuren
O, Kwakkel G. Validity of maximal exercise testing in people with multiple sclerosis and low to moderate levels of disability. Phys Ther. 2014; 94(8): 1168-75.

39. Lim S, Choi SH, Jeong I-K, Kim JH, Moon MK, Park KS, et al. Insulin-sensitizing effects of exercise on adiponectin and retinol-binding protein- 4 concentrations in young and middle-aged women. J Clin Endocrinol Metab. 2008; 93(6): 2263-8.

40. Ponichtera Mulcare JA, Mathews T, Barrett PJ, Gupta SC. Change in aerobic fitness of patients with multiple sclerosis during a 6month training program. Res Sports Med. 1997; 7(3-4): 265-72.

41. Heather A, Paul C. Effects of high-intensity resistance training on strength, mobility, balance, and fatigue in individuals with multiple sclerosis: a randomized controlled trial. J Neurol. 2011; 35: 2-10.

42. Niessner A, Richter B, Penka M, Steiner S, Strasser $\mathrm{B}, \mathrm{Ziegler} \mathrm{S}$, et al. Endurance training reduces circulating in flammatory markers in persons at risk of coronary events: impact on plaque stabiliza tion. Atherosclerosis. 2006; 186: 160-5.

43. Ribeiro F, Alves AJ, Duarte JA, Oliveira J. Is exercise training an effective therapy targeting endothelial dysfu nction and vascular wall inflammation. Int $\mathrm{J}$ Cardiol. 2010; 141: 214-21. 